\title{
JUDICIALIZAÇÃO PARA A PAVIMENTAÇÃO DE RUAS
}

\author{
Judicialization for street paving
}

\section{Antonio Fernando de Amorim Cadete}

Graduado em Direito pela Universidade Federal de Pernambuco. Especialista em Direito Público pela Faculdade Estácio do Recife. Procurador do Município da Procuradoria Geral do Município de João Pessoa. Advogado da Advocacia.

\section{Leon Delácio de Oliveira e Silva}

Mestre em Desenvolvimento Urbano pela Universidade Federal de Pernambuco, UFPE. Especialista em Direito Constitucional Aplicado pela Faculdade de Direito Prof. Damásio de Jesus. Bacharel em Direito pela Universidade Católica de Pernambuco, UNICAP. Procurador do Município de João Pessoa/PB. Professor. Advogado.

\begin{abstract}
Resumo
O objetivo do presente trabalho será tratar sobre a viabilidade do ajuizamento de ações contra o poder executivo municipal para a pavimentação de ruas. Para tanto, analisaremos quais direitos sociais estariam relacionados a essa temática, expondo a natureza jurídica das vias públicas no ordenamento jurídico brasileiro, bem como a exposição dos principais aspectos acerca da judicialização das políticas públicas, reunindo as principais teses a respeito do tema. Utiliza-se o método hipotético-dedutivo, com pesquisa bibliográfica utilizando livros, obras em meios eletrônicos e legislação. Como resultado, esperamos demonstrar que a despeito de o planejamento das políticas públicas de estado ser matéria tipicamente adstrita às competências do Poder Executivo, nos casos de demonstrada ofensa a direitos fundamentais de cunho social o Poder Judiciário, quando provocado, deve atuar no sentido de suprir os planos municipais a fim de evitar lesão a direitos.
\end{abstract}

Palavras-chave: Políticas públicas. Judicialização. Vias públicas. Pavimentação. Mobilidade urbana. Sustentabilidade. Planejamento.

\section{Abstract}

The aim of this paper will be to study the possibility of judicialization against the municipal executive branch for paving streets. To this end, we will analyze which social rights would be related to this theme, exposing the legal nature of public roads in the Brazilian legal system, as well as the exposure of the main aspects about the judicialization of public policies, bringing together the main theses on the subject. The hypothetical-deductive method is used, with bibliographic research using books, electronic works and legislation. As a result, we hope to demonstrate that, although state public policy planning is typically a matter for the powers of the executive branch, in cases of demonstrated offense to fundamental social rights, the judiciary, when provoked, should act to supply municipal plans to prevent damage to rights.

Keywords: Public policy. Judicialization. Roads. Paving. Urban mobility. Sustainability. Planning.

\section{Sumário}

1. Os direitos fundamentais e a pavimentação de ruas; 2. Principais doutrinas sobre a judicialização das políticas públicas;

3. Conclusão; 4. Notas; Referências 


\title{
1. OS DIREITOS FUNDAMENTAIS E A PAVIMENTAÇÃO DE RUAS
}

A ONU não previu, de forma direta, a temática da mobilidade urbana ou da pavimentação de ruas e avenidas como essencial para a consecução do desenvolvimento sustentável. No entanto, o desenvolvimento das cidades com necessários "sistemas de transporte seguros, acessíveis, sustentáveis e a preço acessível para todos" foi temática eleita pela ONU como objetivo da humanidade a ser alcançados até o ano de 2030.

Assim, em futuro próximo tornar-se-ão intensas as atividades visando o cumprimento das metas fixadas internacionalmente, inclusive com a participação do Brasil, o que certamente acirrará o debate acerca da possiblidade de intervenção do Poder Judiciário para sanar eventuais falhas de atuação na implementação desses serviços relacionados.

As Nações Unidas (ONU) definiram os Objetivos de Desenvolvimento Sustentável (ODS) como parte de uma agenda do desenvolvimento sustentável. Lançada em setembro de 2015 durante a Cúpula de Desenvolvimento Sustentável das Nações Unidas (ONU). Os ODS's constituem uma nova agenda para o desenvolvimento, traçando 17 objetivos que nortearão a atuação da comunidade internacional até o ano de 2030. Especificamente o Objetivos 11, conhecido como o ODS Urbano, por tratar de cidade e comunidades sustentáveis, teve redação que aqui merece destaque específico no item 11.2:

\footnotetext{
Objetivo 11: Tornar as cidades e os assentamentos humanos inclusivos, seguros, resilientes e sustentáveis. [...]

Meta 11.2 Até 2030, proporcionar o acesso a sistemas de transporte seguros, acessíveis, sustentáveis e a preço acessível para todos, melhorando a segurança rodoviária por meio da expansão dos transportes públicos, com especial atenção para as necessidades das pessoas em situação de vulnerabilidade, mulheres, crianças, pessoas com deficiência e idosos. (ONU, 2015).
}

A temática da mobilidade urbana está inserida na Agenda 2030 como essencial para a consecução do desenvolvimento sustentável. Tal como destacado acima, a Meta 11.2 tratou sobre a necessária implantação dos transportes nas cidades para o real alcance do desenvolvimento sustentável, o que demonstra preocupação internacional diretamente relacionada à qualidade de vida dos cidadãos, abrindo espaço para pautas como tempo de deslocamento nos transportes, emissão de poluição, segurança viária, universalidade na oferta, acessibilidade, e inclusão social.

\begin{abstract}
Para se ter qualidade de vida em uma sociedade, é preciso que se fundamente uma importância relevante à mobilidade urbana, pois ela tem o papel importante na redução do tempo que um indivíduo gasta no trânsito para percorrer seus diversos percursos no dia a dia, sabe-se que menos intensidade no trânsito resulta em menos poluição, congestionamentos e com certeza menos estresse. Portanto a mobilidade urbana possui profunda relação de qualidade de vida para uma comunidade. (GUIMARÃES, 2018, p. 37).
\end{abstract}

O conceito de desenvolvimento sustentável é majoritariamente aceito, como sendo o ponto de equilíbrio, ou a intersecção de três dimensões do desenvolvimento: o social, o econômico e o ambiental, o que ficou conhecido como triple bottom line. Tal conceituação tripartite segue a linha adotada pelo Relatório Brundtland em 1987.

Surgiu, então, o triple bottom line, definido por Jonh Elkington, atentando para a necessidade de se integrar o social ao ambiental e ao econômico, formando o tripé para possibilitar o desenvolvimento sustentável. Nessa linha, o "desenvolvimento sustentável" foi proposto como um ideal a ser atingido, através de um processo qualificativo de produção, efetuado dentro de critérios de respeito aos 
limites ambientais e naturais. [...] Por isso que se tentou alterar a estratégia ou o modelo de sociedade, a fim de possibilitar o crescimento econômico com a preservação ecológica. (SCHRAMM; CORBETTA, 2015, p. 36). (grifos no original).

No ordenamento jurídico brasileiro, a Constituição Federal prevê a competência exclusiva da União de instituir as diretrizes para os transportes urbanos (art. 21, XX), a competência comum (compartilhada entre União, Estados, Distrito Federal e Município) para estabelecer e implantar política de educação para a segurança do trânsito (art. 23, XII), e ainda atribuiu à União a competência privativa para legislar sobre as diretrizes da política nacional de transportes e para legislar sobre trânsito e transporte (art. 22, XI).

Aos Municípios, a Constituição previu, no art. 30, V, a competência para organizar e prestar, diretamente ou sob regime de concessão ou permissão, os serviços públicos de interesse local, incluído o de transporte coletivo, que tem caráter essencial.

Em janeiro de 2012, foi editada a Lei Federal n. ${ }^{\circ}$ 12.587, que instituiu diretrizes da Política Nacional de Mobilidade Urbana, previu que o plano de mobilidade urbana, elaborado em compatibilidade com o plano diretor municipal, seria o principal instrumento de efetivação da Política. A fim de compelir as entidades mirins a prepararem o mencionado planejamento, ficou estabelecido que a omissão implicaria a impossibilidade do recebimento de recursos orçamentários federais destinados à mobilidade urbana. Nos termos da Lei Federal 13.683 de 2018, o prazo para elaboração dos planos pelos municípios se estendeu até o dia 13 de abril de 2019.

No ano de 2014, por meio da Emenda Constitucional n. ${ }^{\circ}$ 2, foi incluído o $§ 10$ ao art. 144 da Constituição para tratar especificamente sobre os serviços de segurança viária. Tal emenda teve o mérito de prever, de forma expressa, no $\$ 10$, I, o direito fundamental à mobilidade urbana eficiente.

O Plano Nacional de Redução de Mortes e Lesões no Trânsito - PNATRANS - foi exigido pela Lei Federal n. ${ }^{\circ} 13.614$ de 2018, tendo sido determinada a sua elaboração conjunta pelos órgãos de saúde, de trânsito, de transporte e de justiça. Segundo o Plano, a segurança viária envolveria a responsabilidade quanto à mobilidade das pessoas e veículos na via, bem como a complexa dinâmica de compartilhamento de espaço, até o estabelecimento de normas de circulação com o objetivo de proteger os usuários e evitar reflexos negativos em todo o aparato estatal (PNATRANS, 2018, p. 11).

A Lei Federal n. ${ }^{\circ} 6.766$ de 1979, que dispõe sobre normas gerais para o parcelamento do solo urbano, prevê que as vias de circulação fazem parte da infraestrutura básica que deve existir nos parcelamentos de solo, não havendo, no entanto, obrigatoriedade a nível nacional para que o loteador execute serviços de pavimentação. Veja-se o seguinte julgado do TJGO:

TJGO. Embargos de Declaração. Processo Judicial n. ${ }^{\circ}$ 512877303.2017.8.09.0051, Rel. CARLOS ALBERTO FRANÇA, 2a Câmara Cível, julgado em 08/08/2018, DJe de 08/08/2018).

[...] I - Realização de obras de pavimentação asfáltica, meio-fio, galerias pluviais, iluminação pública e esgoto. Obrigações não previstas no Decreto de aprovação do loteamento e na legislação de regência. Impossibilidade de imputação à empreendedora. Restando comprovado nos autos que a empresa ré/embargada realizou as obras de infraestrutura básica previstas na Lei n. 6.766/79, na Lei 
Municipal n. 7.222/93 e no Decreto Municipal n. 1.776/2002, que aprovou referido loteamento, bem como cumpriu a publicidade ofertada, deve ser julgado improcedente o pedido inicial de condenação na obrigação de fazer consistente na realização de obras de pavimentação asfáltica, meio-fio, galerias pluviais, iluminação pública e esgoto no loteamento, pois não se pode imputar ao loteador obrigações não assumidas. (TJGO, 2018).

Assim, a despeito de todo o aparato normativo acima delineado, não se pode extrair de forma direta de nosso ordenamento jurídico a previsão de um direito objetivo ou subjetivo para a pavimentação/calçamento de ruas destinadas à circulação humana ou de veículos. Não existe uma determinação legal, de abrangência nacional, que imponha a obrigatoriedade da pavimentação de vias públicas, seja pelo loteador seja pela municipalidade.

A pavimentação das vias seria fato relacionado ao desenvolvimento gradual das cidades, e que não poderia ser, a priori, exigido do Poder Público, sem que esteja relacionado a algum outro fundamento motivador de tal necessidade.

Segundo dados do Censo 2010 do IBGE, 81,7\% dos domicílios particulares permanentes urbanos estariam situados em vias pavimentadas. No entanto, a mesma pesquisa aponta a existência de municípios específicos em que tal percentual cai para zero, como é o caso de Bom Jesus do Araguaia (MT), ou em que tal percentual atinge 100\%, como é o caso de Serra Azul (SP).

O surgimento de uma obrigação jurídica direcionada à pavimentação de vias públicas adviria quando atrelado à efetiva garantia de direitos expressamente previstos em nosso ordenamento, como a garantia de uma mobilidade urbana eficiente (art. 144, §10, CF/88), a garantia do direito social ao transporte (art. $6^{\circ}, \mathrm{CF} / 88$ ), a garantia do direito social à segurança (art. $6^{\circ}$ da CF/88), a garantia do direito à vida (art. $5^{\circ}, \mathrm{CF} / 88$ ), segurança viária (art. 144, $\S 10)$, garantia da dignidade da pessoa humana (art. $1^{\circ}, \mathrm{CF} / 88$ ).

Isso se dá porque a discricionariedade administrativa não é absoluta, pois o agir da autoridade pública é regrado pelo dever jurídico da boa gestão administrativa. Desse modo, o ato discricionário é sempre passível de amplo controle pelo Poder Judiciário, além de ser indispensável a motivação, a fim de que o Judiciário, em caso de impugnação, examine a logicidade entre o pressuposto fático e o ato administrativo. Nesse sentido, segue a excelente lição em forma de acórdão prolatada pelo TRF da $5^{\text {a }}$ Região:

TRF-5. Remessa Ex Officio. Processo Judicial n. ${ }^{\circ} 0002507-89.2011 .4 .05 .8400$, Rel. Des. Fed. Francisco Barros Dias, 2ª T., j. 29 nov. 2011, DJe 01 dez. 2011, p. 615.

[...] 4. Descabida a alegação do DNIT de que é vedado ao Poder Judiciário adentra no mérito da questão ora discutida. $O$ ato discricionário administrativo pode sofrer a apreciação judicial, porquanto, ainda que a autoridade pública tenha o poder de escolha dentre as soluções previstas e permitidas em abstrato, possui ela o dever jurídico da boa gestão administrativa, ou, como ressaltam MARINO PAZZAGLINI FILHO, MÁRCIO FERNANDO ELIAS ROSA e WALDO FAZZIO JÚNIOR, o “...dever jurídico de escolha da providência eficiente, adequada e razoável para alcançar a finalidade da lei reclamada na situação concreta." (Improbidade Administrativa: aspectos jurídicos da defesa do patrimônio público, 4. ed. São Paulo: Atlas, 1999, pág. 21). A discricionariedade administrativa não é absoluta, pois o agir da autoridade pública é regrada pelo dever jurídico da boa gestão administrativa. Desse modo, o ato discricionário é sempre passível de amplo controle pelo Poder Judiciário, além de ser indispensável a motivação, a fim de que o Judiciário, em caso de impugnação, examine a logicidade entre o pressuposto fático e o ato administrativo. 
A pertinência temática entre o asseguramento de direitos previstos constitucionalmente e a necessidade da elaboração de obras de pavimentação de vias públicas, deve decorrer de esforço hermenêutico que fundamente tal imperativo.

Amparado justamente nesse modo de pensar, o Ministério Público Federal no Paraná ajuizou, em 03 jul. 2017, na $1^{\text {a }}$ Vara Federal de Francisco Beltrão (TRF $1^{\text {a }}$ Região), a Ação Civil Pública n. ${ }^{\circ}$ 5002202-45.2017.4.04.7007, contra a União e contra o DNIT ${ }^{1}$, visando ampliar a trafegabilidade da Rodovia BR-163, no trecho entre os municípios paranaenses de Barracão e Santo Antônio do Sudoeste, mediante realização de melhoramento de curvas horizontais, construção de acostamento, diminuição de degrau existente entre a pista e o acostamento, construção de faixas adicionais, de vias marginais, de interseções, de terceiras faixas, de duplicações, de adequações de greide, de passarelas e de contornos de trechos urbanizados. Os pedidos formulados pelo parquet fundamentaram-se em estudos que apontaram a ocorrência de diversos acidentes no trecho, inclusive com morte, ocasionados pelas más condições do capeamento asfáltico.

Nessa linha da argumentação, o Poder Judiciário poderia compelir o Poder Executivo à obrigação de pavimentar via pública desde que comprovado que a não realização da obra irá impactar, de forma significante, direitos fundamentais previstos de forma expressa.

Assim, embora não exista direito à pavimentação de ruas, rodovias ou avenidas, o Estado pode ser compelido à realização dessas obras desde que se comprove que existe ofensa a outros direitos fundamentais previstos na Constituição Federal, sob pena de indevida interferência do Poder Judiciário na formulação de políticas públicas que se inserem no âmbito do planejamento discricionário do Poder Executivo.

Em âmbito municipal a aplicação dos escassos recursos públicos na execução de serviços de pavimentação de ruas deveria observar critérios planejados de mobilidade urbana. Daí a extrema importância a obrigatoriedade de formulação dos planos municipais de mobilidade urbana (imposta aos mesmos municípios que são obrigados a formular planos diretores), que por imposição de lei federal, deveriam ser preparados em consonância com os planos diretores municipais até o prazo limite de janeiro de 2019, sob pena de impedimento de receber recursos orçamentários federais destinados à mobilidade urbana (vide art. $24, \S 1^{\circ}$ e $\S 4^{\circ}$, da Lei Federal n. ${ }^{\circ} 12.587$ de 2012).

Os planos municipais de mobilidade devem orientar os gestores públicos quanto ao exercício do poder discricionário na seleção dos locais prioritários onde serão aplicados recursos, visando à mobilidade urbana eficiente. Desse modo, evitam-se políticas públicas de governo e estimulam-se políticas públicas de Estado, que levam em conta o bem estar duradouro da população como seu motivador maior.

Outros tipos de demandas sociais também devem orientar os gestores para minimizar atuações discricionárias que firam garantias fundamentais da população, como, por exemplo, os aclames dos chamados orçamentos democráticos ou orçamentos participativos, instrumentos de democracia participativa por meio dos quais a população indica aos governantes as prioridades que querem ver atendidas. 
No ano de 2016, foram ajuizadas pelo Ministério Público do Estado da Paraíba, três ações judiciais $^{2}$ visando compelir o Município de João Pessoa a realizar obras e serviços de calçamento, meio fio, linha d'água, drenagem pluvial e esgotamento sanitário de diversas ruas de bairros da capital predominantemente habitados por população de baixa renda.

Seguindo-se a linha tradicional de argumentação, via de regra, não cabe ao Poder Judiciário exercer controle sobre políticas públicas, notadamente no que pertine aos direitos sociais urbanísticos, na medida em que a utilização de recursos para demandas como pavimentação de ruas ou implantação de serviços de saneamento básico requer planejamento global integrado e interdisciplinar entre os Entes Federativos (art. 23, IX, da Constituição Federal), diante da impossibilidade de sua efetividade na forma de atuações isoladas e pontuais.

No entanto, a partir do momento em que se detecta que existe ofensa de direitos fundamentais causada pela ausência da pavimentação das vias públicas, surge a necessidade de sua execução forçada, que poderá ser determinada pelo Poder Judiciário mediante provocação.

Passaremos a tratar das principais correntes existentes na doutrina que discutem o ativismo judicial na judicialização de políticas públicas.

\section{PRINCIPAIS DOUTRINAS SOBRE A JUDICIALIZAÇÃO DAS POLÍTICAS PÚBLICAS}

A judicialização para a garantia da efetividade dos direitos sociais positivados na Constituição é cenário cada vez mais comum na atualidade jurídica brasileira. Desde assuntos relacionados à obtenção de vagas em creches, passando pelo direito à saúde ou atingindo até mesmo assuntos ligados ao sistema prisional, o ativismo judicial tem se feito presente para sanar omissões indevidas do Poder Público.

Está longe de ser consenso na doutrina a definição exata dos limites para a atuação judicial na intervenção de políticas, existindo diversas correntes a respeito, cada uma com posições antagônicas entre si, porém com argumentos verdadeiramente convincentes.

Segundo Badin (2013, p. 27) toda a literatura que aborda a temática da judicialização de políticas públicas pode ser aglomerada em quatro grandes grupos de abordagem, os quais buscaremos expor de forma sintética a seguir.

Abordagem dogmática/deontológica (ou legalista): neste grupo estão as teorias que sustentam estar todas as respostas a todas as dúvidas surgidas da interpretação da já previamente dadas pela própria lei, e o juiz seria o único intérprete legítimo. Desse modo, ele possuiria uma capacidade pressuposta de descobrir o sentido do interesse público em cada caso concreto. Todas as nuances das políticas públicas (seus fins, meios e prioridades) poderiam ser inferidas objetivamente a partir do texto legal, pois que todas as escolhas já foram tomadas pela lei. Aqui, a judicialização de políticas públicas seria um mero ato de subsunção legal.

Abordagem neoinstitucional/consequencialista: este grupo possui um forte viés eco- 
nômico e prega que a ampla margem de discricionariedade dos juízes, para intervir e modificar, a posteriori, as regras (contratos e leis), com base apenas em raciocínios formais de aplicação do direito, sem qualquer atenção para as consequências econômico-sociais, seria um entraves ao desenvolvimento econômico. Baseia-se na ideia de que juízes bem-intencionados, mas que não ponderam as consequências econômicas de suas decisões, podem promover, de forma paradoxal, resultados maléficos para toda a sociedade. Essa linha de abordagem possui raízes na Análise Econômica do Direito (Law \& Economics), enfatizando a importância dos efeitos econômicos das decisões judiciais como critério normativo de justiça.

Abordagem de teoria política/legitimidade: a ideia aqui defendida é no sentido de que a atuação dos juízes na formulação de políticas públicas padeceria de grande déficit democrático, na medida em que não são eleitos e nem arcam com a responsabilidade política das decisões que tomam. Disso decorreria a ameaça da tirania dos juízes, a subverter a normal divisão de atribuições entre os três poderes, pela indevida "intrusão" na arena dos poderes políticos do Estado. Soma-se a isso o argumento de que o Poder Judiciário seria uma instituição de difícil acesso, e apenas as pessoas que já participam dos debates públicos é que conseguiriam promover ações. Assim poderia estar havendo uma reorganização de recursos públicos para uma parcela da população que já bem representada no processo democrático, ou seja, promoveria, em última instância concentração de gastos públicos em camadas sociais de maior renda.

Abordagem da crítica à capacidade institucional: os autores reunidos neste tópico defendem ideias no sentido de que a desconexão entre intenção e resultado da ação judicial poderia ser explicada pelos estudos empreendidos segundo a abordagem da "capacidade institucional", centrada na crítica da invasão dos espaços políticos pelos órgãos judiciários sob o ponto de vista da incapacidade de seus instrumentos para resolver esse tipo de disputa. Essa seria a forma condizente com realidade para se tentar traçar as devidas limitações à atuação do judicial review. O judiciário não estaria institucionalmente preparado para lidar com esse tipo de conflito pois seria um formulador errático de políticas públicas e um péssimo alocador de recursos. A função de prestação jurisdicional não seria compatível com a formulação de políticas públicas por uma série de fatores, dentre eles: necessidade de adstrição ao caso concreto; efeito inter partes das decisões judiciais; o processo judicial não daria margem à revisão de suas políticas (coisa julgada); contraditório bilateral não se adequaria à natureza plurilateral dos conflitos distributivos; princípio da inércia militaria em favor apenas daqueles que têm condições de invocar a proteção do judiciário; ignorância dos juízes a respeito de matérias técnicas, etc.

Podemos visualizar que cada um dos quatro grupos de argumentação acima elencados possui argumentos plausíveis e ao mesmo tempo contrários entre si.

O fato é que, com a edificação do Estado do Bem-Estar Social, acompanhada da positivação dos direitos humanos de segunda geração (direitos sociais), os juízes foram alavancados à categoria de agentes políticos, e entre a omissão cega e o ativismo exacerbado, buscam encontrar seu lugar na efetivação das garantias constitucionais da forma mais republicana possível. 
Assim, como decorrência da proibição do non liquet, previsto no art. $5^{\circ}, \mathrm{XXXV}$, de nossa Constituição Federal ("a lei não excluirá da apreciação do Poder Judiciário lesão ou ameaça a direito"), tendo em vista a inafastabilidade do controle jurisdicional de políticas públicas, melhor seria discutir os limites para essa atuação, e não sua possibilidade em si, que já é revelada como plenamente possível.

Ocorre que não existe no ordenamento jurídico previsões positivadas acerca dos limites possíveis para a atuação judicial em casos de que envolvam políticas públicas. Assim, melhor seria que os juízes, conscientes de tal fato, analisassem qual a instituição pública que seria mais apta a definir o destino da política pública naquele caso concreto, procedendo-se a uma análise institucional comparada.

A depender de quem formule uma política pública, imbuído do desejo real de promover o interesse público, podem ser obtidas posições diferentes, como bem colocaram Vianna e Burgos (2005, p. 32) estudando uma Ação Civil Pública que objetivava a criação de leitos para crianças e jovens dependentes de álcool e drogas. Segundo os autores, os membros do Ministério Público, autores da ação, possuíam uma visão de como deveria ser traçada a política pública de saúde, completamente distinta da visão de uma pesquisadora teórica na área de saúde pública. Além disso, ambas as visões já seriam distintas daquela sustentada pelo gestor de saúde mental do município. Segundo Badin (2013, p. 95), "em uma frase, a escolha de quem escolhe pode ser a escolha do que se escolhe."

Não se pode olvidar acerca do constante embate envolvente da dicotomia entre o mínimo existencial e a reserva do possível no que atine à judicialização de políticas públicas. Seria sindicável pelo Poder Judiciário intervir, por via de exceção, nas políticas públicas a fim de garantir o mínimo existencial aos cidadãos, e mesmo assim, desde que observada a reserva do possível, dentro dos limites da razoabilidade e das capacidades financeiras e técnicas do ente público.

Premissa central da análise que se passa a empreender é a circunstância de que não se poderá desconsiderar que o direito à saúde, como os demais direitos fundamentais, encontra-se sempre e de algum modo afetado pela assim designada reserva do possível em suas diversas manifestações, seja pela disponibilidade de recursos existentes (que abrange também a própria estrutura organizacional e a disponibilidade de tecnologias eficientes), seja pela capacidade jurídica (e técnica) de deles se dispor (princípio da reserva do possível). Por outro lado, a garantia (implícita) de um direito fundamental ao mínimo existencial opera como parâmetro mínimo dessa efetividade, impedindo tanto omissões quanto medidas de proteção e promoção insuficientes por parte dos atores estatais, assim como na esfera das relações entre particulares, quando for o caso. Em outras palavras e apenas retomando aqui o que já havia sido anunciado, em matéria de tutela do mínimo existencial (o que no campo da saúde, pela sua conexão com os bens mais significativos para a pessoa) há que reconhecer um direito subjetivo definitivo a prestações e uma cogente tutela defensiva, de tal sorte que, em regra, razões vinculadas à reserva do possível não devem prevalecer como argumento a, por si só, afastar a satisfação do direito e exigência do cumprimento dos deveres, tanto conexos quanto autônomos, já que nem o princípio da reserva parlamentar em matéria orçamentária nem o da separação dos poderes assumem feições absolutas. (SARLET; FIGUEIREDO, 2008, p. 28).

No que pertine à judicialização de políticas ligadas à saúde pública, tendo em vista os fortes ditames constitucionais que garantem, de forma seca e direta, que "a saúde é direito de todos e dever do Estado", e tendo em vista a sua direta ligação com o direito à vida 
(axiologicamente superior aos demais direitos fundamentais), resta relativamente simples a solução das demandas judiciais resultando, quase que inevitavelmente, pela concessão do tratamento médico pleiteado.

No entanto, torna-se mais complicada a solução quando em debate a judicialização de direitos sociais que não se relacionam de forma direta com o direito à vida, como é o caso de eventual ação judicial que pleiteie a implementação de infraestrutura relacionada à pavimentação asfáltica de vias públicas.

A solução é de difícil alcance, e deve ser observada por meio de análise casuística quanto aos princípios fundamentais que estariam em colisão, a fim de que o Poder Judiciário possa adotar postura que sem adentrar no mérito propriamente dito do ato administrativo, exerça o regular controle de legalidade, e assim, faça cessar eventuais ilegalidades na atuação (ou na omissão) do Poder Executivo. Tal solução depende de grande esforço hermenêutico que justifique a imposição forçada de atuação dos gestores públicos.

\section{CONCLUSÃO}

Tal como exposto acima, acreditamos que não existe em nosso ordenamento jurídico previsão normativa que tutele de forma direta e específica a obrigação da pavimentação de vias pelo Estado. Nessa linha, as obras e serviços direcionados para esse fim seriam fruto da atuação típica, autônoma e independente do Poder Executivo de elaborar e implementar políticas públicas.

No entanto, para evitar omissões injustificadas no exercício das funções discricionárias do Poder Executivo, e para garantir coerência aos ditames republicanos, é necessária que atuação do Poder Judiciário esteja atenta para assegurar a efetividade aos direitos fundamentais.

Nessa linha, a despeito do vácuo legislativo, a obrigação jurídica para a execução de pavimentações de vias públicas pode ser reconhecida e determinada pelo Judiciário ante a necessidade de garantia do mínimo existencial de direitos expressamente tutelados pela ordem jurídica, tais como a garantia de uma mobilidade urbana eficiente (art. 144, §10, $\mathrm{CF} / 88$ ), a garantia do direito social ao transporte (art. $6^{\circ}, \mathrm{CF} / 88$ ), a garantia do direito social à segurança (art. $6^{\circ}$ da $\mathrm{CF} / 88$ ), a garantia do direito à vida (art. $5^{\circ}, \mathrm{CF} / 88$ ), garantia da segurança viária (art. 144, §10), ou a garantia da dignidade da pessoa humana (art. $1^{\circ}, \mathrm{CF} / 88$ ).

\section{NOTAS}

1. O Departamento Nacional de Infraestrutura de Transportes (DNIT) possui natureza jurídica de autarquia federal, tendo por objetivo institucional "implementar a política de infraestrutura do Sistema Federal de Viação, compreendendo sua operação, manutenção, restauração ou reposição, adequação de capacidade e ampliação mediante construção de novas vias e terminais. Os recursos para a execução das obras são da União. Ou seja, o órgão é gestor e executor, sob a jurisdição do Ministério dos Transportes, das vias navegáveis, ferrovias e rodovias federais, instalações de vias de transbordo e de interface intermodal e instalações portuárias fluviais e lacustres. Além disso, o DNIT, é o órgão da União competente para exercer as atribuições elencadas no art. 21 do Código de Trânsito Brasileiro: nas rodovias federais, ele é responsável pela aplicação de multas por excesso de peso e ou de velocidade, por meio dos postos 
de pesagem e das lombadas eletrônicas." (DNIT, 2019).

2. Trata-se dos processos n. ${ }^{\circ}$ 0812914-27.2016.8.15.2001, 0813727-54.2016.8.15.2001, 081371455.2016.8.15.2001, tendo como objeto a pavimentação de diversas ruas dos bairros do Muçumagro, Conjunto Padre Juarez Benício, Grotão/João Paulo II, respectivamente.

\section{REFERÊNCIAS}

BADIN, Arthur Sanchez. O controle judicial das políticas públicas. Contribuição ao estudo do tema da judicialização da política pela abordagem da análise institucional comparada de Neil K. Komesar. São Paulo: Malheiros Editores, 2013.

DNIT - Departamento Nacional de Infraestrutura de Transportes. Brasília, 2019. Disponível em: http:// www.dnit.gov.br/acesso-a-informacao/perguntas-frequentes. Acesso em: 30 jun. 2019.

GUIMARÃES, Francisco de Assis Batista. As condições de mobilidade urbana na rua Francisco Lopes de Almeida na cidade de Campina Grande-PB. Monografia (Trabalho de Conclusão de Curso de Graduação em Geografia) - Universidade Estadual da Paraíba, Campina Grande, 2018. Disponível em: http://dspace.bc.uepb.edu.br/jspui/handle/123456789/17057. Acesso em: 30 jun. 2019.

IBGE. Censo demográfico de 2010: aglomerados subnormais e informações territoriais. Rio de Janeiro, 2010. Disponível em: https://biblioteca.ibge.gov.br/pt/biblioteca-catalogo?view=detalhes\&id=7552. Acesso em: 22 ago. 2010.

ONU - ORGANIZAÇÃO DAS NAÇÕES UNIDAS. Objetivos do Desenvolvimento Sustentável. Nova lorque, 2015. Disponível em: https://nacoesunidas.org/pos2015/agenda2030/. Acesso em: 30 jun. 2019.

PNATRANS. Plano Nacional de Redução de Mortes e Lesões no Trânsito. Brasília, 2018. Disponível em: http://www.brasil.gov.br/noticias/cidadania-e-inclusao/2018/09/governo-lanca-plano-com-metas-parareduzir-mortes-no-transito-pela-metade/livro-pnatran.pdf. Acesso em: 30 jun. 2019.

SARLET, Ingo Wolfgang; FIGUEIREDO, Mariana Filchtiner. Reserva do possível, mínimo existencial e direito à saúde: algumas aproximações. Revista de Doutrina da $4^{\text {a }}$ Região. Porto Alegre: n. ${ }^{0} 24$, jul. 2008. Disponível em: http://www.revistadoutrina.trf4.jus.br/artigos/edicao024/ingo_mariana.html. Acesso em: 30 jun. 2019.

SCHRAMM, Alexandre Murilo; CORBETTA, Janiara Maldaner. Desenvolvimento sustentável e sustentabilidade: conceitos antagônicos ou compatíveis? Sustentabilidade meio ambiente e sociedade: reflexões e perspectivas. E-book. Umuarama: Universidade Paranaense-UNIPAR, 2015. p. 36. Disponível em: http://pos.unipar.br/files/publicao_academica/9d5a3a3d7ba6979f415c36893428525d.pdf. Acesso em: 30 jun. 2019.

TJGO. Processo Judicial n. ${ }^{\circ}$ 5128773-03.2017.8.09.0051, Rel. Carlos Alberto França, 2a Câmara Cível. DJe de 08 ago. 2018. Disponível em: https://www.tjgo.jus.br/index.php/processos/atos-judiciaisjurisprudencia. Acesso em: 30 jun. 2019.

VIANNA, Luiz Werneck; BURGOS, Marcelo Baumann. Entre princípios e regras: cinco estudos de caso de ação civil pública. Rio de Janeiro: Escola da Magistratura do Rio de Janeiro, 2005. 
Recebido em: 30/06/2019

Aceito em: 09/09/2019 